\title{
Technical Note: Rainfall simulator runoff hydrograph analysis
}

\author{
GARY W. FRASIER, MARK WELTZ, AND LAURA WELTZ
}

Authors are Research Hydraulic Engineer, USDA-ARS, Rangeland Resources Research, 1701 Center Ave. Fort Collins, Colo. 80526, Hydrologist-Research Leader, USDA-ARS, Southwest Watershed Research Center, 2000 East Allen Road. Tucson, Ariz. 85719 and Consultant, 4810 N. Desert Tortoise Pl., Tucson, Ariz. 85745, formerly Research Assistant, Colorado State University, Fon Collins, Colo. 80523.

\begin{abstract}
Rainfall simulators have been used more than 50 years to evaluate hydrologic parameters. The generated runoff hydrograph is a continuous integration of all factors that affect runoff flow. The complexity and interaction of site factors on runoff and infiltration processes makes it difficult to identify a single component of the hydrograph that accurately characterizes the entire runoff event. A technique was developed to separate the runoff hydrograph into segments representative of different portions of the flow event. Each segment grouping is anulyzed for treatment and/or site factor differences or influences on the runoff. Comparing the treatment or site impacts on each hydrograph component allows a more detailed interpretation of the runoff and infiltration processes. This approach to runoff hydrograph analysis makes it possible to quantitatively assess differences in rainfall simulator runoff results and provide insight into why hydrographs may be similar or different.
\end{abstract}

Key Words: rangeland, hydrology, runoff/infiltration, simulation

Rainfall simulators are a tool that has been used for more than 50 years to evaluate hydrologic parameters such as infiltration, runoff, erosion, and sediment yield (Robinson 1979, Neff 1979). They can apply reasonably reproducible quantities and intensities of water to areas up to 10 's of square meters.

While the runoff hydrograph from a rainfall simulator plot appears to be a simple picture of the runoff event, it represents a continuous integration of all factors that affect the runoff flow such as surface roughness, infiltration rate, water application rate, plot slope, and vegetation composition and density. Some of these factors are constant with time during the runoff event, ie., plot slope and vegetation composition. Other factors, such as infiltration rate change with time. Because of the complexity and interaction of site factors, it is difficult and maybe erroneous to select a single component or portion of the runoff hydrograph to characterize the runoff process or to use as a determinant in evaluating treatments or watershed performance. The following technique was developed for analyzing runoff hydrographs from rainfall simulator studies to better understand the effect of site factors or treatments on the runuff process.

Manuscript accepted 20 Mar. 1998

\section{Background}

Runoff rates from simulation plots can be determined by point volumetric measurements at periodic intervals, recording volume changes with time in a calibrated tank, or using small flumes or weirs equipped with water stage recorders or more recently, electronic data loggers. These data are used to create the runoff hydrographs.

Past data analysis of runoff hydrographs have usually used one of the following techniques:

1. Ratio of total runoff volume to total water applied (Rauzi and Hanson 1966).

2. Ratio of runoff rate to water application rate at some arbitrary time following runoff initiation (Simanton et al. 1991, Warren et al. 1986b), at several specific times during the runoff event (Warren et al. 1986a, Thurow et al. 1986) or at some specified time after 30 minutes (Weltz et al. 1989).

It is difficult to compare results of different studies that do not use the same portion of the hydrograph (runoff event) as the critical factor.

There are a limited number of techniques that have been developed for evaluating the entire hydrograph. One technique is the synthetic hydrograph, ie. the unit hydrograph, which is defined as the direct runoff hydrograph resulting from unit depth of excess rainfall produced by a uniform intensity storm of specified duration (Sherman 1932). Another method is the SCS peak discharge method estimated from the triangular approximation of the hydrograph with linear rising and falling limbs (Pilgrim and Cordery 1993). Wu et al. (1978) developed a goodness-of-fit test to test differences between hydrographs with simulated rainfall from plots of uniform area. These techniques permit general comparison of treatment effects but they are not suited for interpreting the time related processes that affect the runoff/infiltration processes.

Typical problems associated with trying to evaluate a treatment effect without considering the entire hydrograph can be demonstrated using actual runoff hydrographs from 4 plots selected from a series of rainfall simulator studies conducted on semiarid rangelands (Fig. 1). These hydrographs are from studies evaluating the effects of long-term cattle grazing native shortgrass rangelands on runoff and infiltration. Study sites were on the Central Plains Experimental Range (CPER) near Nunn, Colo. and on the High Plains Grasslands Research Station (HPGRS) near Cheyenne, Wyo. (Frasier et al. 1995, 1996). The selected plots were on similar soil types and slopes with similar plant composition and density. 

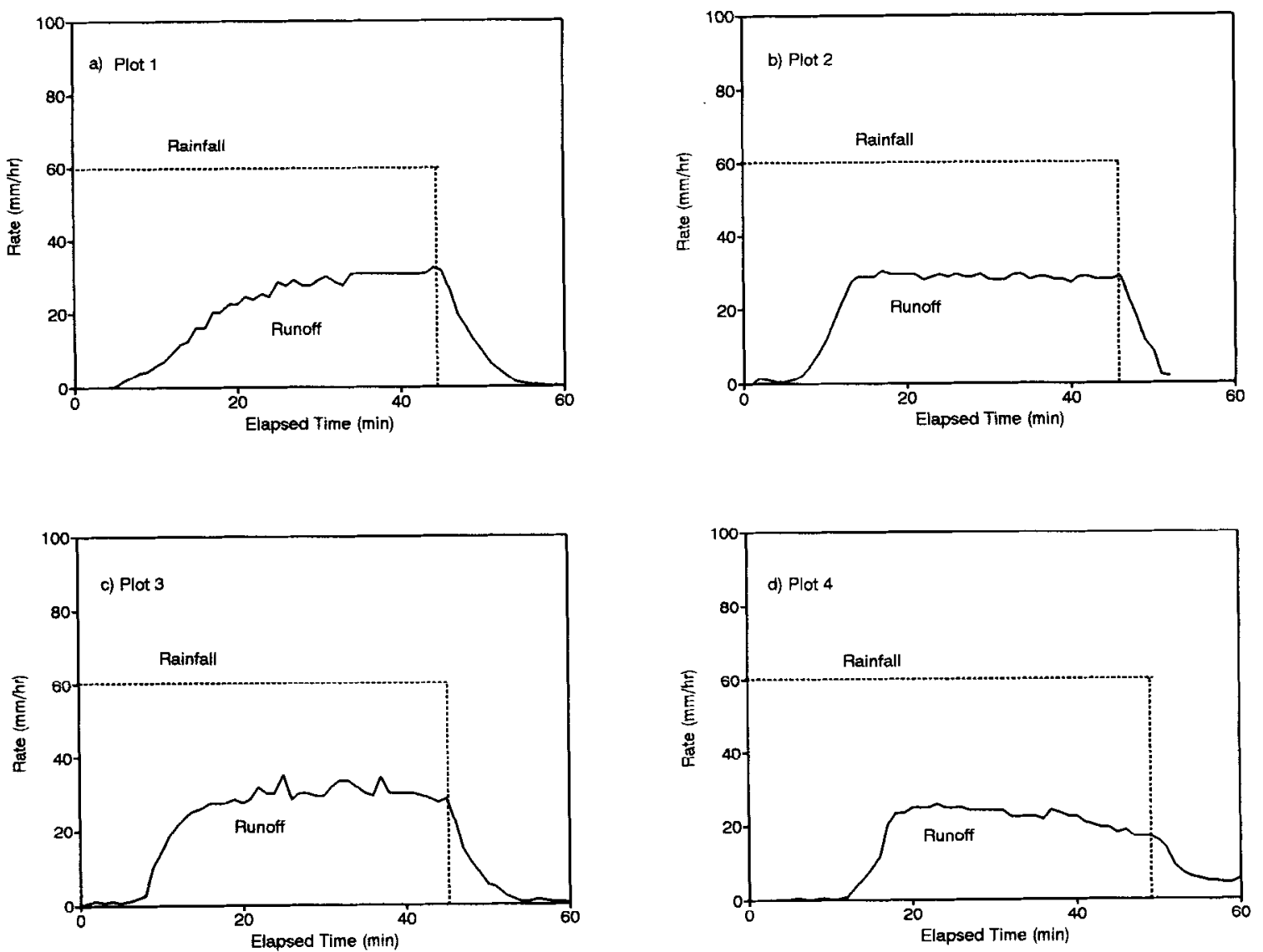

Fig. 1. Four rainfall simulator hydrographs from shortgrass prairie rangelands.

A rotating boom rainfall simulator was used to apply water at a nominal rate of $60 \mathrm{~mm} \mathrm{hr}^{-1}$ to $3-\times 10-\mathrm{m}$ plots. Water application rate was measured and recorded at $1-\mathrm{min}$ intervals with a $20-\mathrm{cm}$ $D$ raingage equipped with a bubble flow meter. The total water applied to each plot was measured with 6 small plastic raingages located within the plot boundary. Water collection troughs at the lower edge of each plot collected and directed the runoff water through a small critical depth flume. Depth of water flowing through the flumes was measured and recorded at $1-\mathrm{min}$ intervals.

Inspection of the 4 runoff hydrographs (Fig 1) reveals some general common as well as dissimilar features.

Similar features:

A. Peak or maximum runoff rate is approximately the same for all plots $(25-35 \mathrm{~mm} / \mathrm{hr})$.

B. Equilibrium runoff rate for plots 1 through 3 is the same $(28-30 \mathrm{~mm} / \mathrm{hr})$.

Dissimilar features:

A. Plot 1 has a gradual increase in runoff rate (rising limb) which merges to the equilibrium runoff rate.

B. Plot 2 has a rapid increase in the rate of runoff which abruptly changes to the equilibrium runoff rate.

C. Plot 3 has an initial rapid increase in rising limb runoff rate which gradually merges with the equilibrium runoff rate.

D. Plot 4 has a very rapid rate of increase in the rising limb runoff rate to a peak value followed by a decline in runoff with time.
Several different conclusions concerning the similarities or differences in runoff among the plots can be derived from the data. If accumulative runoff volume is used as the indicator of treatment performance, then the plots may be different depending upon the time interval used in the evaluation (Table 1). At 20 minutes into the simulation, total accumulative runoff from plots 1 and 4 is less than from plots 2 and 3. Plot 1 has less accumulative runoff at 45 minutes and total than the other 3 plots. These comparisons limit the determination of factors or periods that are most important in the runoff process.

In analyzing rainfall simulator data, one must recognize natural precipitation characteristics that might affect runoff rates and quantities in field settings. What size of storms are most prevalent? What is the most probable storm duration? What are the storm intensities for the most probable storm? To illustrate some of the variability in these factors, selected periods of unpublished rainfall data sets from 2 Agriculutrual Research Service (ARS) locations were analyzed. The data was collected from a research site near Phoenix, Arizona (GR) and from the Central Plains Experimental Range (CPER) near Nunn, Colo. The Phoenix, Ariz. data was collected during the summer "monsoon" period (1 May-30 Sep) for the period of 1965 through 1979. The Nunn, Colo. data was from 1 April through 30 Oct for 2 years, 1993 and 1995. The rainfall was measured with weighing raingages and recorded on 8 day analog charts. Each raingage chart was analyzed using the breakpoint technique described by Brakensiek et al. 1979. Any period of 10 to 15 minutes with no discernable change in the raingage trace was considered a break in the storm event. 
Table 1. Runoff hydrograph charasteristics of 4 plots from rainfall simulation studies in semi-arid rangeland

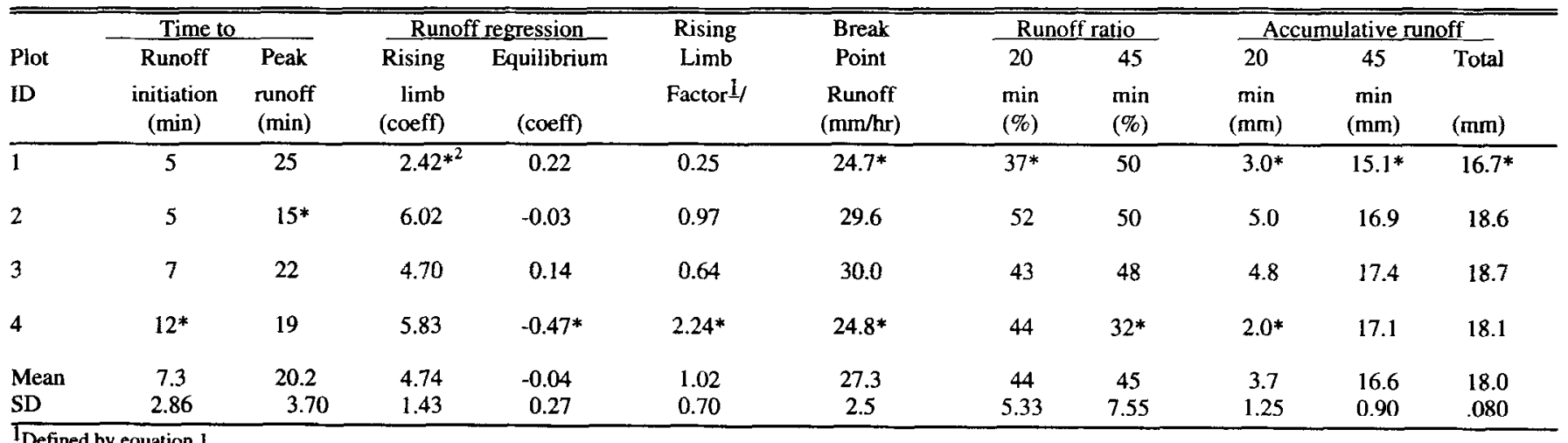

1 Defined by equation 1 .

2* Denotes value greater/smaller than one standard deviation from other plots.

Despite the differences in the locations of the study sites, several of the rainfall characteristics are remarkedly similar (Fig. 2). Approximately $50 \%$ of the total number of storms had durations of less than $30 \mathrm{~min}$. These short duration storms also represented the highest average storm intensities and were frequently the largest storm sizes. Thus in some situations or locations we should focus on the first $30 \mathrm{~min}$ of the rainfall simulator event. This illustrates that some general storm characteristics may aid in the selection of critical component(s) of the rainfall simulator hydrograph for analysis. We believe it is desirable to compare all or at least several of the hydrograph components before arriving at a conclusion as to the differcnces or similarities in runoff processes among treatments.

Our approach is to separate the hydrograph into segments representing different portions of the flow event. If desired, statistical comparisons of treatment effects can be made for each different part. By independently evaluating each portion of the hydrograph, one may gain insight into which site and/or experiment factors are most impacting the runoff and infiltration processes.

\section{Procedure}

Even with the rotating boom simulators, variable rates of water supply and wind factors can affect the total water applied to a plot although run times and rainfall intensities are controlled or believed the same (Simanton et al. 1991). To account for possible differences in water application rate between simulator runs and during a simulator run, the runoff rate (Fig. 1) is adjusted by the water application rate (rain) for each recorded time (Fig. 3).

The runoff hydrograph is separated into 3 sections, time to runoff initiation, rate of change in runoff during the rising limb, and equilibrium runoff rate. The end points of the segments (rising limb and equilibrium runoff phases) are determined using the break-point approach originally developed for analyzing precipitation data (Brakensiek et al. 1979). This approach uses an iterative least squares regression analysis and maximizes the coefficient of determination for the rising limb and equilibrium runoff segments of the hydrograph (Fig. 3). On simulator studies using multiple rainfall intensities, the hydrographs are separated into additional segments representing the rising and equilibrium stages for each phase (Weltz 1995).

\section{Results and Discussion}

In many rangeland situations the runoff characteristics at the beginning of the storm are the most important (storm durations are too short to develop full equilibrium runoff). For example, how long does it take before runoff occurs (runoff initiation), or

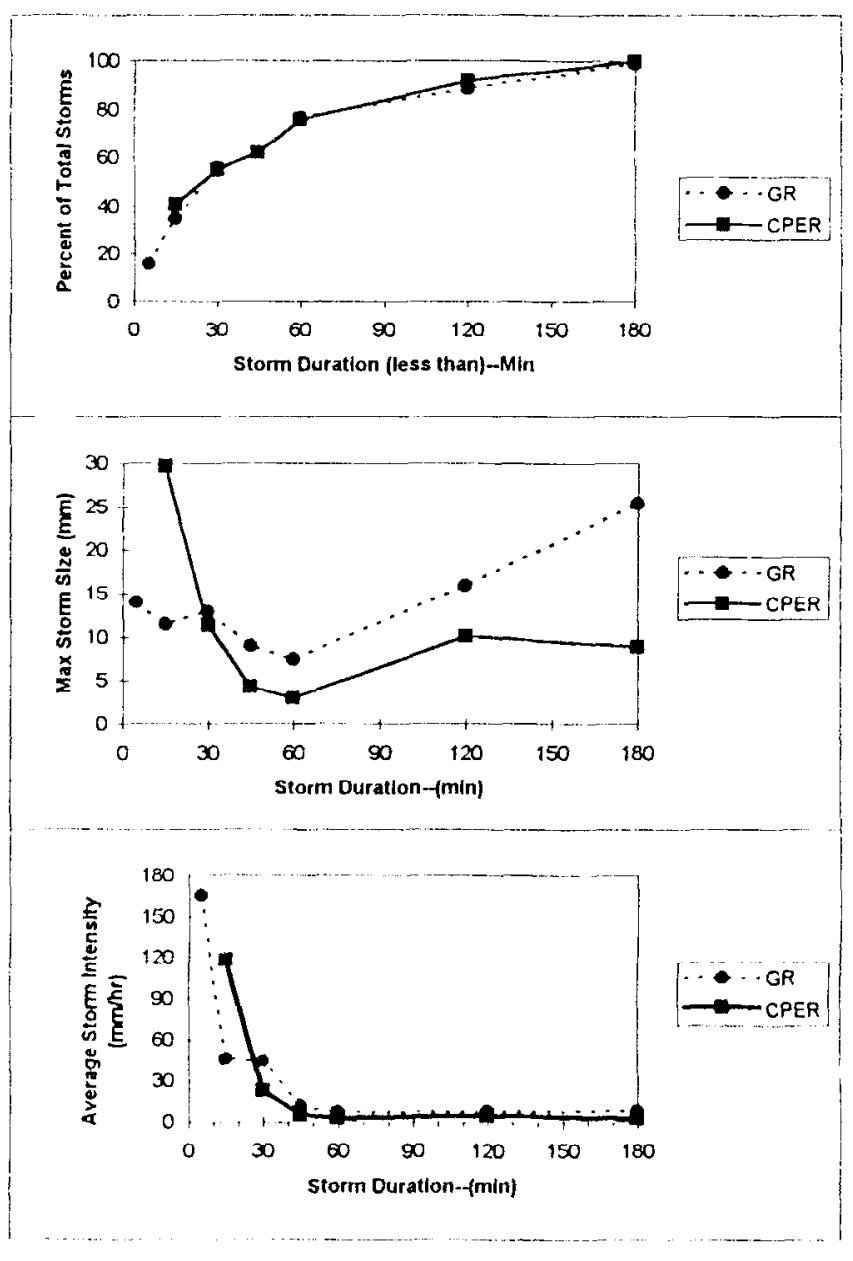

Fig. 2. Individual rainfall storm event characteristics at 2 locations: GR near Phoenix, Arizona; CPER near Nunn, Colo. 

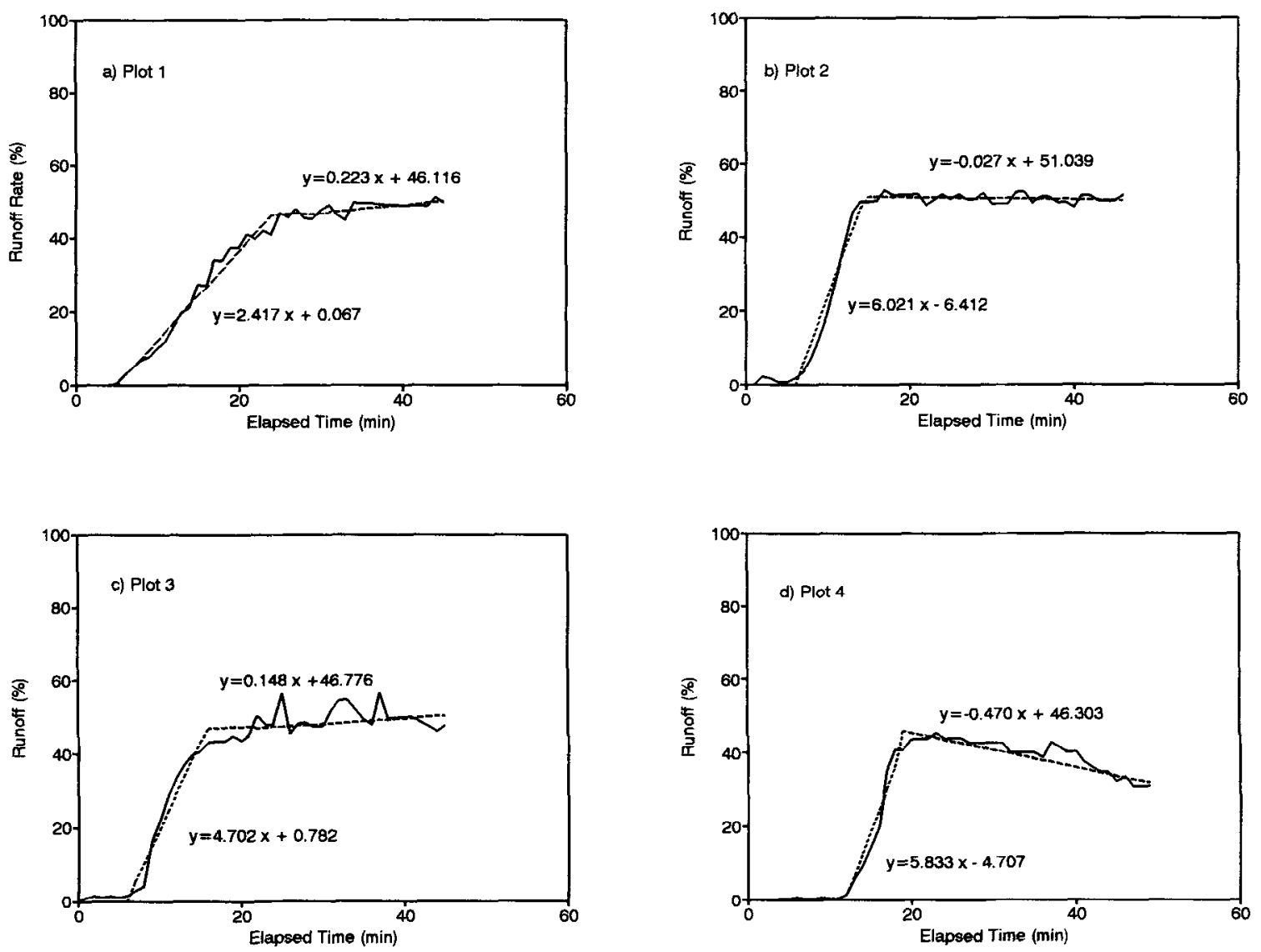

Fig. 3. Runoff efficiency for the 4 simulated runoff hydrographs with superimposed best fit linear regression lines on rising limb and equilibrium portion.

how long does it take to reach peak runoff (rising limb runoff rate) are frequently important questions concerning potential water erosion problems.

Initially all the water infiltrates into the soil as it is applied. As the soil wets and becomes saturated the rate of water infiltration declines and eventually excess water ponds in surface depressions. When the smallest surface depressions are filled, runoff starts (runoff initiation). The time to runoff initiation is affected by the number and sizes of the surface depression storages in conjunction with plot slope (increasing the plot slope reduces the relative quantity of water retained in surface depressions). For a time following runoff initiation, runoff rate usually increases rapidly as more of the surface depressions overflow (rising limb of the runoff hydrograph). The rate of change of runoff during the rising limb phase is affected by both infiltration rate and surface features such as depression storage, micro-channel connectivity, surface roughness, plant stem density, and plant species composition. Once all the depressions are filled and overflowing there is a "leveling off" as the runoff rate approaches a steady state. In many instances, the runoff rate gradually increases because of decreasing infiltration with time. The runoff rate during this period is frequently referred to as "equilibrium runoff" even though there may still be minor increases in the runoff rate. This equilibrium runoff is controlled by the soil matrix and soil water potential. Using the runoff regression coefficient during the equilibrium period as a criteria, traditional runoff models would have a positive value of the runoff coefficient (Figs. 3 Plots 1 and 3). A negative value for the equilibrium runoff coefficient (Figs. 3 Plots 2 and 4) indicates water infiltration increasing with time (runoff decreasing with time) after peak runoff has been achieved. This situation can result from a surface crusting or water repellency that dissipates with time (DeBano 1975, Savage 1975.

All of these components of the runoff hydrograph are important in evaluating the impact of treatment or site effects. The 3 hydrograph characteristics, time to runoff initiation, regression coefficient of rising limb, and equilibrium runoff factors for the 4 example plots (Fig. 1) are tabulated in Table 1. Time to runoff initiation on plot 4 was approximately twice as long as on the other 3 plots. The regression coefficient of the rising limb for plot 1 was approximately one half of the other 3 plots. The regression coefficient for the equilibrium phase for plot 4 had a significant negative slope. Other characteristics such as time to peak runoff and runoff ratio (\%) at 20 and 45 minutes show similar differences among the 4 plots. Even though these plots could be considered similar, hased on equilibrium runoff rates (Fig. 1), comparison of different portions of the runoff hydrograph indicate dissimilar runoff relations. The specific plots which are different depends upon the specific characteristic selected (Table 1).

Another approach in hydrograph analysis is to combine selected characteristics into a single factor that can be compared across plots. Since the initial portion of the rainfall event is an important period in many areas, we propose multiplying the slope of the rising limb of the hydrograph by the ratio of lag in time from the 
beginning of rainfall until runoff starts (defined as time to runoff initiation) divided by the lag in time from the beginning of rainfall to the time at peak runoff (defined as the duration of the rising limb).

Rising Limb Factor $=\frac{\text { Peak runoff rate }}{\text { Time to runoff peak }} X \frac{\text { Time to runoff initiation }}{\text { Duration of rising limb }}$

This factor gives a unique value for each rising limb of the hydrograph. Table 1 shows the computed factors for the 4 hydrographs of Figure 1. The rising limb factor in combination with the equilibrium runoff regression coefficient provide a unique description of the complete hydrograph with only 2 determinants (multiple rainfall intensity hydrograph will require additional ratios). This analysis of the 4 plots indicate that plot 4 has a different runoff characteristic (rising limb factor 2.24 and equilibrium runoff coefficient 0.47 ) than the other 3 plots (rising limb factor less than 1.0 and equilibrium runoff coefficient flat to positive slope ).

\section{Applications and Implications}

Interaction of micro-topography and vegetation on surface storage capacity is one of the major factors that creates confusion between rainfall simulator results and data from natural rainfall induced runoff. The measured rate of runoff from an area is an integrated resultant of the water applied minus the water retained on the soil and plant surfaces complex and the amount infiltrated into the soil. The effective or apparent infiltration rate on a hillslope for most rangelands is a nonlinear function of rainfall intensity, the distribution and quantity of canopy and ground cover, and soil characteristics.

For many rangeland areas, rainfall consists of bursts of high intensity rainfall followed by reduced rainfall or brief periods of no rainfall and then intense rainfall rates again. During the periods of high intensity rainfall the surface storage areas overtop and runoff is produced. During times of lower rainfall intensity the water stored in surface storage areas infiltrates and must be filled again during the next high rainfall burst. There is no true equilibrium runoff period. This fluctuation in rainfall intensities contributes to the phenomenon of apparent infiltration rate or runoff changing as a function of rainfall intensity (Morin and Kosovsky 1995). A second cause of changes in apparent infiltration rates is that runoff generated in bare interspaces does not generally flow long distances downslope before it is intercepted by vegetation clumps that can absorb all or a portion of the runoff depending on its infiltration capacity.

This approach to runoff hydrograph analysis makes it possible to quantitatively assess some of the differences in rainfall simulator runoff results and may provide insight into why hydrographs are similar or different and how the results might be applied to natural rainfall events on rangelands.

\section{Literature Cited}

Brakensiek, D.L., H.B. Osborn, and W.J. Rawls. 1979. Field manual for research in agricultural hydrology. USDA-SEA Agr.Handb. No. 224. 548 pgs.

DeBano, L.F.,1975. Infiltration, evaporation and water movement as related to water repellency. In: B.A. Steward (Editor) SSSA Special Publ. Series No. 7 Soil Sci. Soc. Amer. pgs 155-164.
Frasier, G.W., R.H. Hart, and G.E. Schuman. 1995. Rainfall simulation to evaluate infiltration/runoff characteristics of a shortgrass prairie. J. Soil and Water Cons. 50(5):460-463.

Frasier, G.W., R.H. Hart, and G.E. Schuman. 1996. Impact of grazing intensity on infiltration/runoff characteristics of a shortgrass prairie. In: Neil E. West (Editor) Proc. 5th International Rangeland Congress Vol.1, Soc. Range Manage. Denver, Colo. pp 159-160.

Morin, J. and A. Kosovsky. 1995. The surface infiltration model. J. Soil and Water Cons.50(5):470-476.

Neff, E. L., 1979. Why rainfall simulation?. Proc. Rainfall Simulator Workshop, Tucson, Ariz. March 7-9, 1979, USDA-SEA Agr. Rev. and Manuals. ARM-W-10. pgs. 3-7.

Pilgrim, D. H. and I. Cordery. 1993. Flood runoff. In: D. R. Maidment (Editor) Handbook of hydrology. McGraw-Hill, Inc. New York, N.Y. pp 9.1-9-41.

Rauzi, F. and C. L. Hanson. 1966. Water intake and runoff as affected by intensity of grazing. J. Range Manage. 19(6):351-356.

Robinson, A.R., 1979. Comments-Rainfall simulator workshop. Proc. Rainfall Simulator Workshop, Tucson, Ariz. March 7-9, 1979, USDASEA Agr. Rev, and Manuals. ARM-W-10. pgs. 1-2.

Savage, S.M., 1975. Occurrences and nature of fire-induced soil water repellency. In: B.A.Steward (Editor) SSSA Special Publ. Series No. 7 Soil Sci. Soc. Amer. pgs 164-169.

Sherman, L.K., 1932. Streamflow from rainfall by unit-graph method. Eng. News-Record. 108:501-505.

Simanton, J.R., M.A. Weltz, and H.D. Larsen. 1991. Rangeland experiments to parameterize the water erosion prediction project model: vegetation canopy cover effects. J. Range Manage. 44(3):276-282.

Thurow, T.L., W.H. Blackburn, and C.A. Taylor, Jr. 1986. Hydrologic characteristics of vegetation types as affected by livestock grazing systems, Edwards Plateau, Texas. J. Range Manage. 39(6): 505-509.

Warren, S.D., W.H. Blackburn, and C.A. Taylor, Jr. 1986a. Soil hydrologic response to number of pastures and stocking density under intensive rotation grazing. J. Range Manage. 39(6):500-504.

Warren, S.D., T.L. Thurow, W.H. Blackburn, and N.E. Garza. 1986b. The influence of livestock trampling under intensive rotation grazing on soil hydrologic characteristics. J. Range Manage. 39(6):491-495.

Weltz, L., 1995. Hydrologic response of shortgrass plant communities. Master Thesis, Colorado State Univ., Fort Collins, Colo. 40 pgs.

Weltz, M., M. K. Wood, and E. E. Parker. 1989. Flash grazing and trampling: effects on infiltration rates and sediment yield on a selected New Mexico range site. J. Arid Environ. 16:95-100.

Wu, Y., V. Yevjevich, and D. A. Woolhiser. 1978. Effects of surface roughness and its spatial distribution on runoff hydrographs. Colorado State Univ. Hydrology papers., 96. Fort Collins, Colo. 